ciously made one incision down the whole / affection. It was not, lowever, one of length of the swelling. It would be found such a dangerous character as is somethat such incisions were by far the most ef- times seen; in fact, in these climates, the fectual mens of treatment in phlegmonous termination of acute hepatitis in supputrysipelas, and of terminatmy satisfactorily ration is comparatively of infrequent occurthe local symptoms and general disturbance. rence. He was bled to sixteen ounces. Had When erysipelas is accompanied by inflam- jalap and calomel, and a saline mixture, with mation of the subjacent cellular tissue, it tartar emetic and sulphate of magnesia, every frequently evinces a disposition to spread; sixth hour. He was moreover cupped ouce, We adhesive inflammation, in other words, and had a blister to the side. He continued does not intervene to arrest its progress; in these cases free incisions are also by far the best means of counteracting the disease. In the first place they occasion a copious flow of blood from the inflamed parts, the ressels blceding with infinitely greater energy than is observed in ordinary wounds of the same extent; but the relief is not solely attributable to the bleeding, for an equal quantity abstracted by other means will always fail to produce an equivalent effect. The incisions, however, operate most effectually, by relieving the great distension of the parts; the limb, previously red and shining;, becomes pale and wrinkled, and the pain is almost immediately abated. In the present case the incision operated in this manner; the spreading of the local in. flammation has been arrested, and the pa. tient now only labours under a simple healthy wound.

ACUTE HEPATITIS, TERMINATING IN SUPPURATION.

He had occasion once or twice to notice the application of the same principles of treatment to internal and exterual inflammations. There were at present some cases in the wards which illustrated this analogy further. In "Henry" there was a patient named George Booth, at. 39, admitted with a large phlegmonous abscess over the right bip, and who also laboured under hepatitis. Generally speaking, one inflammation was as much as the animal economy could undertake at a time; but, in this case, two were in action. He had been unwell about a fortnight before admission, but could assign no cause for his illness. He said his hip lad been "lanced" by a doctor, but nothing followed but blood. As he felt a deep fuctuation, he introduced the lancet a little further, and a copious discharge of pus immedıately followed. Still the relief was not so great as might have been expected; the skin was sallow, his features contracted, and he complained of pain in his right side. $\mathrm{O}_{\mathrm{u}}$ uncovering his abdomen, the cause was at once perceptible; he breathed entirely by bis ribs, and studiously avoided the exercise of the abdominal portion of his bellows. These appearances, coupled with great abdominal pain and other usual indications, at once proved the nature of the taking one grain of calomel and five of jalap till his bowels were effectually relieyed, and till it was considered the purging had been carried to a sufficient extent. Active as this was, however, none of the bad consequences were produced on the intestinal mucous membrane, of which our brethren on the other side of the channel seemed so much afraid.

Under this treatment the man had noarly recovered. In these cases he would again repeat, that the same principles of cure which referred to external inflammation, were also applicable to those of internal parts. There were some other patients then under treatment which further illustrated this position, but of these he would speak at the next lecture.

\section{INQUEST AT HAMPTON.}

\section{LETTER FROM MR. MORSON.}

\section{To the Editor of $\mathrm{T}_{\mathrm{H}} \mathrm{L}$ Lancet.}

SIr,-Anticipating some comments would be made from the report which you gave in your publication of the 9 th October, of the inquest held at Hampton on the 2nd, I purposely delayed offering any observations before, anxious to asceriain first the feelings of that respectable body of men denominated "General Practitioners" from the result of the case in question, the practice of one of whom, it appears, in the instance of Mr. Bowen, has recently most unjustly been called in question, and, as far as $I$ am capable of giving an opinion, been made the subject of unmerited animadversion.

Previously to my noticing any portion of the report taken at the inquest, and embodied in No. 371 of your LANCET, I must pause for a while to express freely the surprise and indignation which I felt on perusing a letter from Sir Andrew Halliday (exphysician to the Duke of Clarence), published in your 372nd Number, and in which I find he has endeavoured, but in a very pitiful manner, to exculpate himself from what he would wish others to regard, as merely "an apparent inconsistency," in reference to his original assertion to $\mathrm{Mr}$. Sells, of Kingston, and that afterwards made 
to Mr. Taylor. The conduct, Sir, lately/sufficiently authorised to interfere, recome practised by Sir Andrew throughout the mended Mr. Sells to apply to the church. whole of this most unpleasant affair, I can wardens of Hampton; he did so, and it was have no hesitation in pronouncing, to have in consequence of this application that the been perfectly at variance with the criteria churchwardens met, and convened all those by which $I$ have been taught to estimate persons who were in attendance with MIr. the conduct of truth and honour; and he Bowen on the deceased previously to ber himself must be well aware, that I am not death; when, after a patient and minute singular in this opinion, or without proof examination of each, which lasted five " as strong as boly writ" to justify it. I bours, and when depositious were recorded now, Mr. Editor, boldly call upon Sir An- which materially differ from those subsedrew to account for the five different asser- quently taken at the inqucst, they were in. tions which he made, respecting the removal duced (upon hearing a further statement of of the arms of the child, and the non-delivery of the woman. 1st, To Messrs. Sells and Taylor ; 2nd, To Mr. Jackson; 3rd, To Mr. Bowen and myself; 4 th, To the Coroner and jury ; and 5 th, After the inquest, in th the letter which he addressed to Mr. Taylor; no two of which, I do assure you, Sir, in the least correspond. Ihus far, I trust, I have adduced enough to satisfy you, and your enlightened readers, that Sir Andrew's conduct sarours of something more than "apparent inconsistency." Also, that the assertion which he has since made in your Journal, accusing others of having used "great efforts to implicate him personally," is, like the rest of his statements, wholly without foundation.

Already I fear, Sir, you will consider me as trespassing largely upon.valuable pages, but as you have afforded space for the attack, you will, I hope, in justice, grant a similar favour for the defence.

It was not until the morning of the 26th August, that Mr. Bowen was apprised of what (as since proved) had been secretly hatching for a month before. At this time Mr. Kent, an inhabitant of Hampton, at the request of the minister, called on him to say, that his attendance was required at the re. sidence of Mr. Jackson, where the parish authorities were sitting in council. Mr. Bowen, notwithstanding this very brief notice, having had no prior intimation that such meeting was to take place until an hour after the witnesses had assembled, rea-. dily obeyed the summons, when, on arriving at the field of action, to his great surprise he was informed, that his presence had been requested to answer to the charge of improper treatment towards the late Frances Clarke, who was represented to have died, a month previously, in the pains of labour, during his attendance upon her. This charge Mr. Howen was likewise informed, was preferred against him by Mr. Sells, a surgeon at Kingsion, who, without giving him any antecedent notalication of his intentions (although they had met each other firequently after the death of the deceased), had applied to a magistrate to take cognizance of the case. Mr. Cowe, of Sunbury (the magistrate applied to), not deeming himself

the case given by Mr. Bowen) to appeal to three eminent obstetric practitioners of this metropolis for their opinions ; and as these gentlemen all agreed as to the propriety of the treatment pursued, they (the clurch. wardens) immediately expressed their ap. probation of Mr. Bowen's conduct, in a let. ter which this gentleman receired a few days after. Tbus, Sir, you will observe, that the statement in your report, which informs us " that some inquiry was entered into by the parish officers, but this only went 10 ascertain how far the surgeon at T'edding. ton was culpable in declining to attend," is perfectly erroneous. The meeting was in. stituted for the purpose of investigating the foundation for Mr. Sells's charge, and I believe with a view also of allowing this individual, and all others interested, the opportunity of substantiating the same; but, strange to say, Mr. Sells never came for. ward; and lest ignorance of the meeting might be alleged by Mr. Gury (retained, as asserted, on behalf of Mr. Clarke) as the cause of his non-attendance, it is but justice to say, that during the sitting of the church. wardens, a letter, written by him, was re. ceived by Mr. Jackson, containing instructions, and such questions as he wished to be put to the witnesses, and which u'ere puts This obvious listlessness on the part of $\mathrm{MI}$. Guy, I leave for him to explain; it must, however, unquestionably suffice to show, that he at least was well acquainted with what was going on, and if, as he has since vaunted, it was "ever his practice to tread lightly on the accused," why did he not then generously come forward, and allow Mr. Bowen the opportunity of repelling aspersions, as unfounded in their nature as they were ma. lignant and prejudicial in their tendency? But no, Mr. Editor, this was an act of plain dealing hardly to be expected.

For the satisfaction of your readers, re. mote from the scene of this late disgraceful transaction, it may not be amiss to state that Mr. Bowen, the gentleman accused of ignorance and inlumanity, has, for nearly the last three years, filled the situation of visiting assistant to Mr. Davies; during this period his conduct proved always 80 uniformly correct; the opportuuities which 
Le bad of exercising his profession were so who, by contrasting both, will, I am quite extensive and multifarious, the satisfaction assured, discover the conflicting nature of he afforded to those of every class committed such testimony, as well as the very apparent to his care had been so universal; nay, so motives which led to its elicitation. beloved and well known was he througbout the neighbourhood, for mildness and assiduity in his profession, that upon Mr. Daries's relinquishing lis practice at Hampton 10 become domestic surgeon to their most gracious Majesties, many of his patients, the greater part of whom are individuals of the utmost respectability, opulence, and rank, solicited Mr. Bowen to become Mr. Davies's successor. Arrangements for this purpose were accordingly made, and I beg it will be borne in recollection, that it was not until a few days before Mr. Davies's final departure from Hampton to accompany the King to Brighton (fully one month after the death of the deceased), that this attack was made. Hence Mr. Bowen has every legiti. mate right to infer, that those persons who propagated the report of his improper treatment of the deceased were influenced in doing so, by motives other than purely philanthropic and humane. Inasmuch as he is prepared to prove that the very witness, An Ellam, who bore testimony against him, declared, very shortly after the demise of Frances Clarke, to Mr. Keene, a gentleman of property residing in the parish of Teddington, and one of its overseers, that MIr. Bowen's conduct to the deceased had been most " kind and attentive." Inasmuch as Mr. Clarke, the widower of the deceased, acknowledxed to a gentleman, a resident of Hampton (whose name, if required, I am authorized to give), when asked how he intended to remunerate $\mathrm{Mr}$. Guv, replied, "I can only do so with my gratitude, but I have some good friends who I have every reason to hope will do so for me." Who these good friends are, Mr. Bowen has yet to find out, together with many other circumstances upon which "clouds, sliades, aud darkness, rest." These slight abstracts will, however, I hope, suffice to prove that although it has been maintained, that the proceedings which took place were instituted at the sole desire of the husband, such could not have been the case; also, that throughout the whole business Mr. Bowen has had to contend with some secret miscreant, who, like the owl which fears to prey by day, was compelled to seek for nightly cover for the exe. cution of his base designs.

I shall now, Sir, go on and briefly offer a $f \in t$ additional remarks on the evidence taken before the parish officers at Hampton prior to the inquest, and that which was subseruently obtained, and since recorded in your Journal of the 9 h inst. To this part of $m y$ communication I beg leave more particularly to invite the attention of your readers,

One of the witnesses, Mary Ann Elliott, when examined by the parish authorities, on the morning of the 26th of August, stated, " that on her mentioning to Mr. Bowen hat Mrs. Clarke wished to have further assistance, he insisted on some other medical gentleman being sent for, stating, at the same time, that there was no use of sending for any one from Hampton, as bo knew there was no one at home."

Ann Ellam deposed on oath to the coroner and jury, that when sbe asked the deceased, in the presence of Mr. Bowen, if she would not like to have some other medical man? "Mr. Bowen said nothing to this."

On the contrary, Sarah Chillman, the midwife, likewise on oath, contradicts the before-mentioned statement of Ann Ellam, and says that when she asked the deceased if she would have Mr. Taylor who attended her before, and when deceased replied she would, that she then told Mr. Bowen; he said, "If Mr. Taylor came, he would go out of the house."

Many more such-like discrepancies in the evidence I could wish freely to expose. But I fear, in doing so, I should only be obtruding upon your valuable time and indulgence. Let it then suffice to say, that upon the " mens conscia recti," and upon the decision given by that tribunal before which Mr. Bowen has lately so unfeelingly been arraigned, but which decision $I$ regret to say was never accurately published, as will be seen from the following correct copy of the verdict_-." Died by the visitation of God; and it is our opinion that the medical attendant did all that was possible to be done, to deliver the deceased under the circumstances"- does he rest his claims for future public confidence and approbation. This I am certain will not be denied him, when every circumstance is duly deliberated upon, and when it is more particularly recollected, that when called upon to render his assistance (after another bad positively refused), he did so with alacrity aud good feeling, that his attention during the progress of the labour was prompt and unremitting, that he left her but for a short period, and that then he was obliged to do so (having to visit elsewhere), the whole of Mr. Davies's extensive practice being, at the time, intrusted to his care.

Let those, therefore, disposed, Mr. Editor, to censure M1r. Bowen hastily, remember " He that is without sin, let him cast the first stode." Lam, Sir, yours faithfully,

J. H. Morson, M.R.C.S of Londou.

28, Cockspur Street, Oct. 20, 1330. 